\title{
Effects of combination therapy indacaterol/ glycopyrronium versus tiotropium on moderate to severe COPD: evaluation of impulse oscillometry and exacerbation rate
}

Antonio Molino, Francesca Simioli, Anna Agnese Stanziola, Mauro Mormile, Maria Martino and Maria D'Amato*

\begin{abstract}
Background: Small airways are considered the major site of airflow limitation in COPD. Impulse oscillometry (IOS) is a forced oscillation technique, which provides passive measurement of lung mechanics. It can differentiate small airway from large airway obstruction and is more sensitive than spirometry for peripheral airway disease. In this study the efficacy of the combination of Indacaterol/Glycopirronium (IND/GLY) versus Tiotropium on airway resistance (R5, R20, R5-20), lung reactance (X) and resonant frequency in moderate to severe COPD patients has been evaluated. We also evaluated inspiratory capacity $(\mathrm{IC})$, forced expiratory volume in $1 \mathrm{~s}\left(\mathrm{FEV}_{1}\right)$, forced vital capacity (FVC), exacerbation rate and quality of life.

Methods: Forty patients were monitored with forced oscillation technique and spirometry. Patients were randomized in 2 groups: 20 received fixed dose once daily Indacaterol/Glycopyrronium (Group A) and 20 received single Tiotropium (Group B).

The oscillometry parameters were the measure of resistance in the airways at $5 \mathrm{~Hz}$ (R5), at $20 \mathrm{~Hz}$ (R20) and the lung reactance $(X)$.

Results: There was a statistically significant difference between pre-dosing at $V_{1}$ and at follow up visits in $R_{5}, R_{20}$ and $X$ values in patients receiving dual bronchodilation but not in control group. Pre-dosing IC value at follow up visits in patients receiving dual bronchodilation had a statistical significant variation.

Conclusions: The "new" bronchodilator combination LABA/LAMA significantly reduces bronchial obstruction in small airways too. The oscillometry demonstrated greater sensitivity compared with spirometry for monitoring outcome measures of airway obstruction and the effect of long-term therapy.
\end{abstract}

Keywords: COPD, Impulse oscillometry lung function, Pulmonary function test, Small airway obstruction

\section{Background}

Chronic Obstructive Pulmonary Disease (COPD) is a common, preventable and treatable disease characterized by persistent respiratory symptoms and airflow limitation due to airway and/or alveolar abnormalities [1]. At present, the diagnosis and staging of COPD is difficult, as spirometry alone is unable to evaluate the severity of this disease because early pathological changes in COPD are localized within small airways with diameter $<2 \mathrm{~mm}$

\footnotetext{
* Correspondence: marielladam@hotmail.it

Respiratory Department Federico II University- A.O. "Dei Colli", Via D Fontana, 134, 80128 Naples, Italy
}

to $4 \mathrm{~mm}$. Static lung hyperinflation is often one of the significant challenges in patients with COPD. It is characterised by a decrease in the elastic recoil of the lungs with a premature closure of small airways leading to air trapping [2]. The impact on lung function parameters is expressed by an increase in functional residual capacity (FRC) and a progressive decrease in inspiratory reserve volume and inspiratory capacity (IC) [3]. Spirometry involves a forced expiratory manoeuvre, which may not be the ideal test to detect subtle improvements in airway calibre in COPD due to effort-dependent small airways closure. Furthermore, $\mathrm{FEV}_{1}$ mainly measures the degree 
of obstruction in large and intermediate airways [4, 5] while COPD is a disease mainly residing in the peripheral airways. Other lung function assessments are necessary to describe the disease pattern. Impulse oscillometry (IOS) is easier to perform in COPD patients [6]. It is an effort - independent test performed during normal quiet breathing, thereby obviating expiratory small airways closure and measuring the frequency - dependent airway resistance and reactance $(\mathrm{X})[7]$.

Tiotropium is a long-acting muscarinic antagonist, with a 24-h persistent bronchodilator effect thus given once daily [8]. Actually, according to the Global Initiative for Chronic Obstructive Lung Disease (GOLD) guidelines, the bronchodilation therapy (anticholinergic and $\beta_{2}$-agonists) is central to the pharmacological interventions for COPD. We can use single or double (combination of $\beta_{2}$ agonist and antimuscarinic drug) bronchodilator agent as maintenance therapy for patients with mild to very severe COPD, depending on symptoms severity and exacerbation frequency.

Combining bronchodilators with different mechanism and duration of action may increase the degree of bronchodilation with a lower risk of side-effects compared to increasing dosage of a single bronchodilator $[1,9]$. Fixed dose combinations (FDCs) provide potent bronchodilation versus single agents, with some advantage in terms of convenience and simplicity compared with combinations administered via separate inhalers.

There is evidence from prospective clinical studies indicating greater improvement in lung function with LABA/LAMA combination therapy compared with increasing the dose of a single bronchodilator in patients with moderate-to-severe COPD [9]. The once-daily fixed-dose combination of indacaterol (IND, a LABA) with glycopyrronium (GLY, a LAMA) 110/50 $\mu \mathrm{g}$ combines these two bronchodilators in a single inhaler and is approved for maintenance treatment of patients with moderate to very severe COPD.

However, there are limited data on the effects of the combination IND/GLY on small airways in patients with COPD.

In this study we evaluated the efficacy of the combination of IND/GLY versus Tiotropium alone on IOS parameters in patients with moderate to severe COPD. We also evaluated lung function including inspiratory capacity (IC), as well as exacerbation rate and quality of life.

\section{Methods}

\section{Inclusion criteria}

Male or female aged $\geq 40$ years who had received a diagnosis of moderate-to- severe COPD according to Global Initiative for Chronic Obstructive Lung Disease guidelines [10], and had a post-bronchodilator forced expiratory volume in $1 \mathrm{~s}\left(\mathrm{FEV}_{1}\right)$ of $\geq 30 \%$ to $<80 \%$ of predicted normal, [10] and a post-bronchodilator $\mathrm{FEV}_{1}$ to forced vital capacity (FVC) ratio of $<0.7$ smoking history $>10$ pack/ years; and $>1$ exacerbation in the last 12 months.

\section{Exclusion criteria}

Atopy; exacerbation within 4 weeks before screening, upper respiratory tract infection within 4 weeks before screening; other respiratory conditions such as haemoptysis, asthma, Idiopathic pulmonary fibrosis (IPF), lung cancer, recent history of rib fracture and pneumothorax.

\section{Subjects}

Patient demographics and other baseline characteristics are shown in Table 1.

All patients attended the clinical laboratory for 4 study visits (every three months), from January 2015 to July 2016.

All subjects gave their written informed consent and the study was approved by Ethics Committee (SUN-AO Dei Colli, Naples, Italy).

\section{Study design}

This was a 52-week randomized, open-label, parallel group study carried out in accordance with the Declaration of Helsinki.

Table 1 Characteristics of patients

\begin{tabular}{lllll}
\hline & & $\begin{array}{l}\text { Mean (SD) } \\
\text { IND/GLY }\end{array}$ & $\begin{array}{l}\text { Mean (SD) } \\
\text { Tiotropium }\end{array}$ & $\begin{array}{l}\text { Mean } \\
\text { Total }\end{array}$ \\
\hline Patients (M) & & $20(17)$ & $20(18)$ & \\
Age & & $70.4(7.83)$ & $72.01(6.79)$ & 71.09 \\
BMI & & $27.85(5.54)$ & $27.40(6.02)$ & 27.64 \\
Years from COPD & & $7.45(5.5)$ & $8.3(4.6)$ & 7.81 \\
diagnosis & & & & \\
Smokers/Former & & $3 / 17$ & $1 / 14$ & $4 / 31$ \\
smokers & & & 7 & 15 \\
GOLD Stage & $\mathrm{B}$ & 8 & 3 & 7 \\
& $\mathrm{C}$ & 4 & 5 & 13 \\
& $\mathrm{D}$ & 8 & $1.27(0.39)$ & 1.28 \\
FEV ${ }_{1}$ & $\mathrm{~L}$ & $1.29(0.33)$ & $52.13(11.33)$ & 52.20 \\
& $\%$ & $52.26(9.04)$ & $2.18(0.54)$ & 2.20 \\
FVC & $\mathrm{L}$ & $2.21(0.52)$ & $68.2(9.5)$ & 69.92 \\
& $\%$ & $70.2(9.4)$ & $56.2(9.5)$ & 54.5 \\
IT & $\%$ & $52.6(9.4)$ & $1.64(0.61)$ & 1.636 \\
IC & $\mathrm{L}$ & $1.63(0.59)$ & $69.16(20.16)$ & 68.85 \\
& $\%$ & $68.61(19.87)$ & $5.77(2.12)$ & 5.96 \\
Borg Dyspnea & & $6.1(2.33)$ & & 70.07 \\
Scale & & $71.5(15.97)$ & $68.65(16.32)$ & \\
SGRQ & & & & \\
\hline
\end{tabular}




\section{Protocol steps}

Screening: assessment of COPD diagnosis and assessment of inclusion/exclusion criteria, prescription of a wash out period (Ultra-LABA $72 \mathrm{~h}, \mathrm{LABA}$ and LAMA $48 \mathrm{~h}$, SABA $8 \mathrm{~h}$ ).

Visit $1\left(\mathrm{~T}_{0}\right)$ : the patients filled in a questionnaire, performed lung function assessment, and oscillometry. Then they were randomized in a 1:1 ratio to receive either once daily IND/GLY 110/50 $\mu$ g delivered via the Breezhaler $^{\circ}$ device (Novartis Pharma AG, Basel, Switzerland) or once- daily Tiotropium $2,5 \mu \mathrm{g}$ Respimat $^{\circ}$ device (Boehringer Ingelheim, Ingelheim, Germany). The modality of drug taking was showed to patients and they assumed it. After $1 \mathrm{~h}$ and $3 \mathrm{~h}$ from that time lung function and oscillometry were performed again.

Visit 2 (3 months +/- 1 week), 3 (6 months +/1 week), 4 (12 months $+/-1$ week): the patients filled in the questionnaire, repeated lung function assessment and oscillometry before the intake of daily dose of drug. They assumed the drug and performed again lung function assessment and oscillometry after $1 \mathrm{~h}$ and $3 \mathrm{~h}$ from the drug intake.

At each of the 4 study visits the patients undertook baseline tests (IOS, and spirometry), before inhalation therapy, after $1 \mathrm{~h}$ and $3 \mathrm{~h}$ from inhalation. Additional assessments were performed including the exacerbation analysis, and quality of life score by SGRQ.

Participants attended the department on the same time during each study visit.

\section{Impulse oscillometry}

The IOS system (IOS, Jaeger Master Screen, Jaeger Co, Wurzburg, Germany) noninvasively assesses respiratory mechanics without patient cooperation using small pressure oscillations generated at the mouth during spontaneous breathing. During the test, subjects firmly supported their cheeks while sitting with their neck in a comfortable neutral posture, wearing a nose clip, and tightly sealed their lips around the mouthpiece in order to stabilize the position of their tongue and to avoid buccal air leaks. Whole-breath, inspiratory (insp), and expiratory (exp) IOS measures of resistance measured the total airway resistance at an oscillation frequency of $5 \mathrm{~Hz}$ (R5), central airway resistance at $20 \mathrm{~Hz}$ (R20), peripheral resistance frequency dependence of resistance from 5 to $20 \mathrm{~Hz}$ (R5-R20), reactance at $5 \mathrm{~Hz}$ (X5), and area under the reactance curve (AX) and the resonant frequency (RF). Reported results are the average of 3 technically acceptable periods of 40 to $60 \mathrm{~s}$ of measure. Impulse oscillometry was performed in triplicate according to the manufacturer's instructions [11-13].

\section{Spirometry}

Lung function measurements were performed according to manufacturer's instructions and European Respiratory Society (ERS)/American Thoracic Society (ATS) recommendations $[14,15]$. The reference values used were established by Crapo et al. [16].

The $\mathrm{FEV}_{1}, \mathrm{FVC}$ and the Inspiratory Capacity (IC), were measured using a dry wedge spirometer (Jaeger Co, Wurzburg, Germany). Baseline values at each visit were measured after at least $15 \mathrm{~min}$ of quiet rest, and the results (absolute values and percent predicted) were evaluated. Readings were again performed in triplicate, with the highest $\mathrm{FEV}_{1}$ recorded.

\section{Exacerbations}

A COPD exacerbation is defined as an acute worsening of respiratory symptoms which needs additional therapy, regardless the factors that cause it [17].

\section{Quality of life}

St. George's Respiratory Questionnaire (SGRQ) is a disease-specific questionnaire designed to measure HRQoL in patients with chronic lung diseases. It consists of 17 questions divided into three categories: symptoms (wheeze, cough, and dyspnea), activities that are limited by the disease, and impact on the respondent's social life and mental state. The scores ranges from 0 to 100 , and lower values indicate better health status [18].

\section{Data analysis}

The study was powered at $90 \%$ to detect a $0.1 \mathrm{kPa} \mathrm{L}-1 \mathrm{~s}$ difference in the primary outcome of trough R5, assuming a within subject standard deviation of $0.13 \mathrm{kPa} \mathrm{L}-1 \mathrm{~s}$, and an alpha error of 0.05 (two-tailed) [19]. Students t-tests were used to compare treatment effects at baseline and after chronic dosing. The level of significance set at 0.05 . Exacerbations' analysis on Relative Risk assessment was based.

\section{Results}

Patients

Thirty-five patients completed the study (20 in Ind/Gly group and 15 in Tio group). Mean age was 71.03 years.

\section{Oscillometry}

In Table 2 we compared pre dual bronchodilation values at $\mathrm{V}_{1}$ and $\mathrm{V}_{4}$.

We found a significant difference between pre-dosing $\mathrm{R} 5 \mathrm{~Hz}$ value at $\mathrm{V}_{1}$ and at follow up visits in patients receiving dual bronchodilation (mean difference -0.16 , $95 \%$ CI -0.2829 to $-0.0371, p=0.0122$ ) but not in control group (mean difference $-0.07,95 \%$ CI -0.2332 to $0.0984, p=0.4111)$. $\mathrm{R} 20 \mathrm{~Hz}$ had a similar change (mean difference -0.066 , 95\% CI -0.1255 to -0.0061 , 
Table 2 Pre dual bronchodilation values at $V_{1}$ and $V_{4}$

\begin{tabular}{lll}
\hline & $V_{1}$ Pre dual bronchodilation & $V_{4}$ Pre dual bronchodilation \\
\hline R $5 ~ H z$ & $0.74 \pm 0.23$ & $0.58 \pm 0.13$ \\
R $20 ~ H z$ & $0.45 \pm 0.10$ & $0.38 \pm 0.06$ \\
$X 5 \mathrm{~Hz}$ & $-0.35 \pm 0.16$ & $-0.20 \pm 0.09$ \\
IC & $1.63 \pm 0.59$ & $2.04 \pm 0.57$ \\
SGRQ & $71.5 \pm 15.97$ & $58.25 \pm 15.98$ \\
\hline
\end{tabular}

$p=0.0318)$. Reactance $(\mathrm{X})$ also showed a difference at follow up only in patients receiving dual bronchodilation (mean difference $0.146,95 \%$ CI 0.0586 to 0.2340 , $p=0.0017$ ) (Figs. 1 and 2).

\section{Spirometry}

Lung function was investigated pre and after $1 \mathrm{~h}$ and $3 \mathrm{~h}$ from the assumption of inhaled therapy. At each visit we found that pre-dosing IC value in patients receiving dual bronchodilation had a statistical significant variation (mean difference $+0.41 \mathrm{~L}, 95 \% \mathrm{CI}$ 0.0505 to $0.7695, \mathrm{p}=<0.05)$. Other parameters did not change neither after dual nor after monobronchodilation, $\mathrm{FEV}_{1}$ did not change significantly in cases $(+0.12 \mathrm{~L}, p=0.38)$, and in controls $(-0.6 \mathrm{~L}$, $p=0.76)$. FVC did not change significantly in cases $(+0.0025 \mathrm{~L}, p=0.99)$, and in controls $(+0.01 \mathrm{~L}$, $p=0.92$ ) (Figs. 3, 4, and 5).

\section{Exacerbation rate}

In patients receiving dual bronchodilation, we found a reduction of $66 \%$ of exacerbations ( $R R=0,3383(95 \% \mathrm{CI}$ 0.1722 to $0.6649, p=0.0017)$. Hospitalization rate was not different between the 2 groups, but among patients receiving mono-therapy there were more frequent exacerbators.

\section{Health status}

Comparing $\mathrm{V}_{1}$ and $\mathrm{V}_{4}$ SGRQ, we found a mean difference of -13.25 points (95\% CI 3.024 to 23.4758, $p=0.0125$ ) after dual bronchodilation therapy (Fig. 6).

\section{Discussion}

In this study, the efficacy of a maintenance combination therapy with indacaterol/glycopyrronium versus tiotropium on IOS parameters in patients with moderate to severe COPD was studied. We demonstrated the efficacy of the combination of IND/GLY versus tiotropium on airway resistance (R5, R20, R5-20), lung reactance (X) and resonant frequency. All of them are small airways parameters. We don't find a $\mathrm{FEV}_{1}$ and FVC statistical significance for the small sample size but in many other studies the once-daily fixed-dose combination IND/GLY $110 / 50 \mu \mathrm{g}$ has been shown to significantly improve lung function and patient-reported outcomes (including dyspnea and health status) versus placebo, and versus Tiotropium [20, 21].

In the SPARK study, Wedzicha et al. [22] demonstrated that the dual bronchodilator IND/GLY was superior in preventing mild to severe COPD exacerbations compared with the single long-acting antimuscarinic bronchodilator glycopyrronium, with concomitant improvements in lung function and health status. Subsequently, the SHINE study [23] confirmed that dual bronchodilation with QVA149 provides additional therapeutic benefits compared to the mono-components indacaterol and glycopyrronium, as well as compared to tiotropium, the current gold standard of care, and placebo in patients with moderate-to-severe COPD. The authors demonstrated that improvement in the primary end-point, trough $\mathrm{FEV}_{1}$ was both statistically and clinically significant (considered to be $100 \mathrm{~mL}$ in COPD) over placebo and statistically significant versus

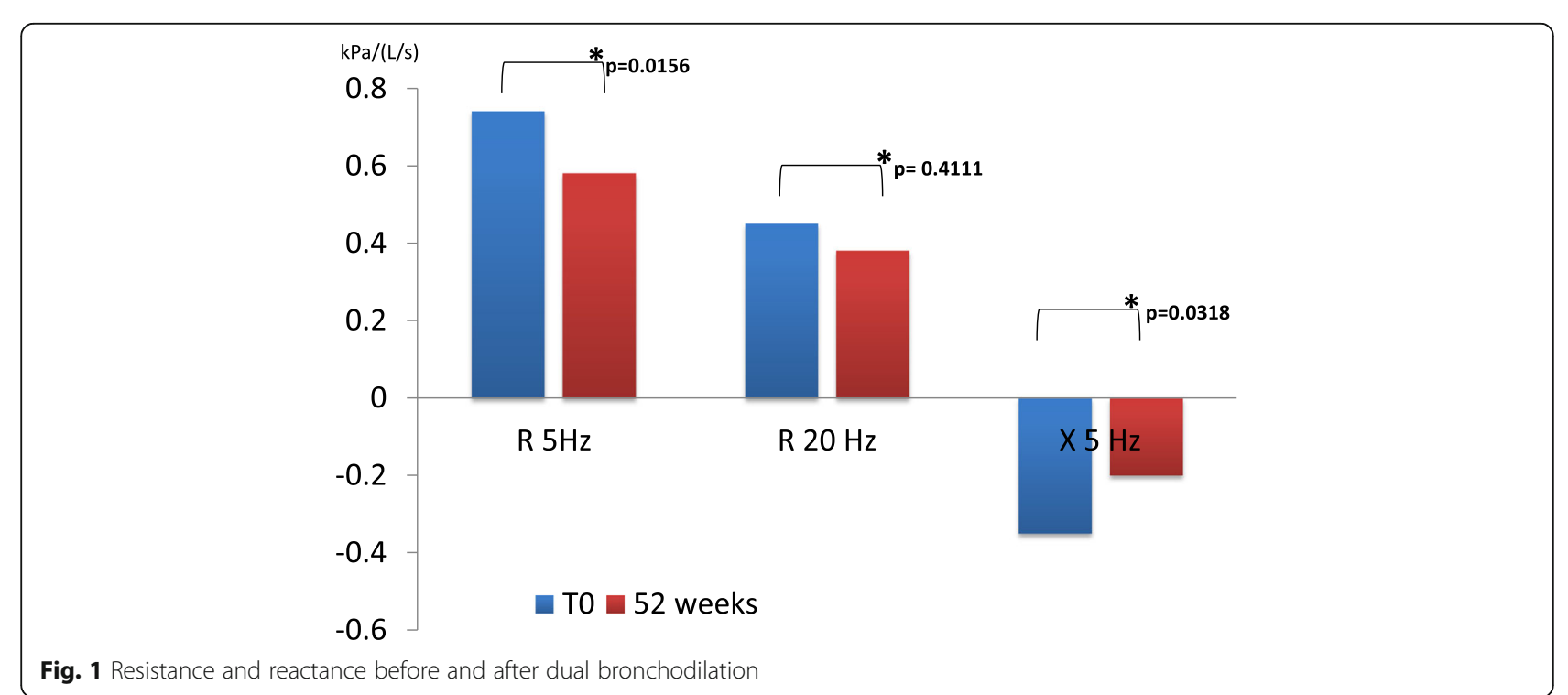




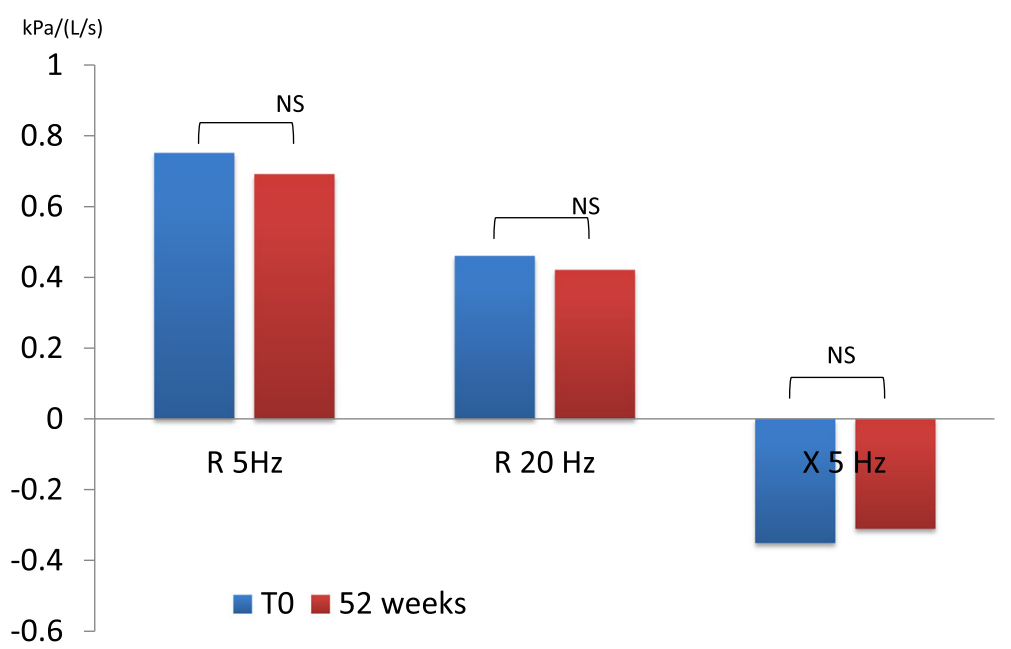

Fig. 2 Resistance and reactance before and after tiotropium

active comparators approaching also clinical significance. IND/GLY also significantly improved TDI total scores compared with tiotropium [21-23].

It is generally accepted that $\mathrm{FEV}_{1}$ is not an optimal parameter for describing the complexity of COPD and that other lung function assessments are necessary to describe the disease pattern $[24,25]$.

Crisafulli et al. in an observational study on stable COPD patients demonstrated that there is a progressive increase in peripheral airway dysfunction among patients with different GOLD stages evaluated by both GOLD staging systems [25]. Furthermore, we demonstrated a strong relationship between small-airway dysfunction (SAD) as assessed by means of IOS and impact of disease [5].

Su-Gang Gong et al. observed that the IOS technologyrelated parameters have high sensitivity in detecting the slightly increased airway resistance that reflects a small airway airflow limitation [26, 27].
Kolsum $\mathrm{U}$ et al. evaluated 94 COPD and 58 out of them were followed up after 1 year. The authors confirmed that IOS measurements are related to the degree of airflow obstruction as measured by forced expiratory volume in $1 \mathrm{~s}$ $\left(\mathrm{FEV}_{1}\right)$, and to the degree of hyperinflation. In addition, he found R5, X5 were all significantly associated $(p<0.05)$ with $\mathrm{FEV}_{1}$, sGaw, TLC, RV and IC but there was no statistically significant change in the $\mathrm{FEV}_{1}, \mathrm{R} 5, \mathrm{X} 5$ after 1 year. For the authors the changes in R5 and R20 did not significantly correlate with the changes in $\mathrm{FEV}_{1}$ [28].

It is known that bronchodilators increase airway diameters and decrease airway resistance making the pattern of airway obstruction more homogeneous in COPD patients [1]. The airway's parameters of spirometry and the IOS are considered in the assessment of physiological changes in the large and small airways separately. Among these spirometric parameters, $\mathrm{FEV}_{1}$ is not well suited to assess the abnormalities in the small airways and is characterized as a large-airway parameter.

\section{FEV1}

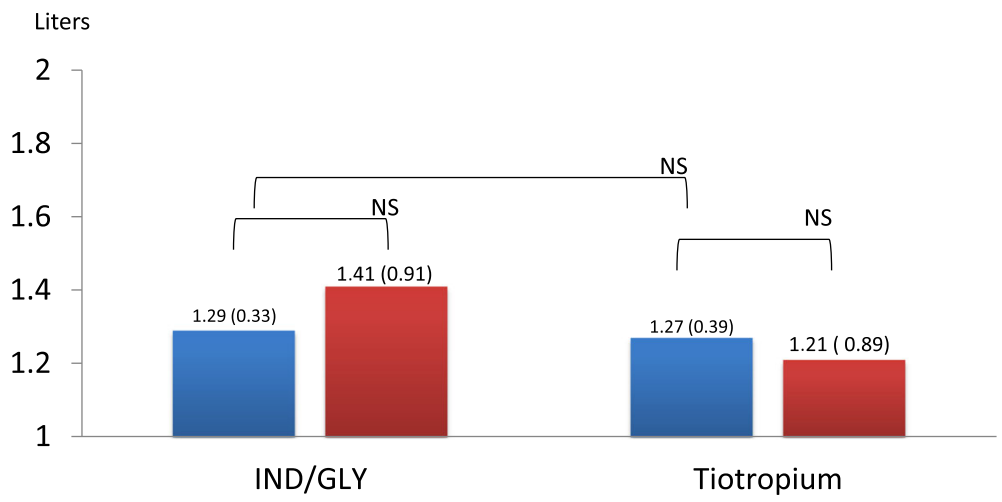

Fig. 3 Pre-dosing Fev ${ }_{1}$ (liters and DS) in two groups at $\mathrm{T}_{0}$ and after 52 weeks 


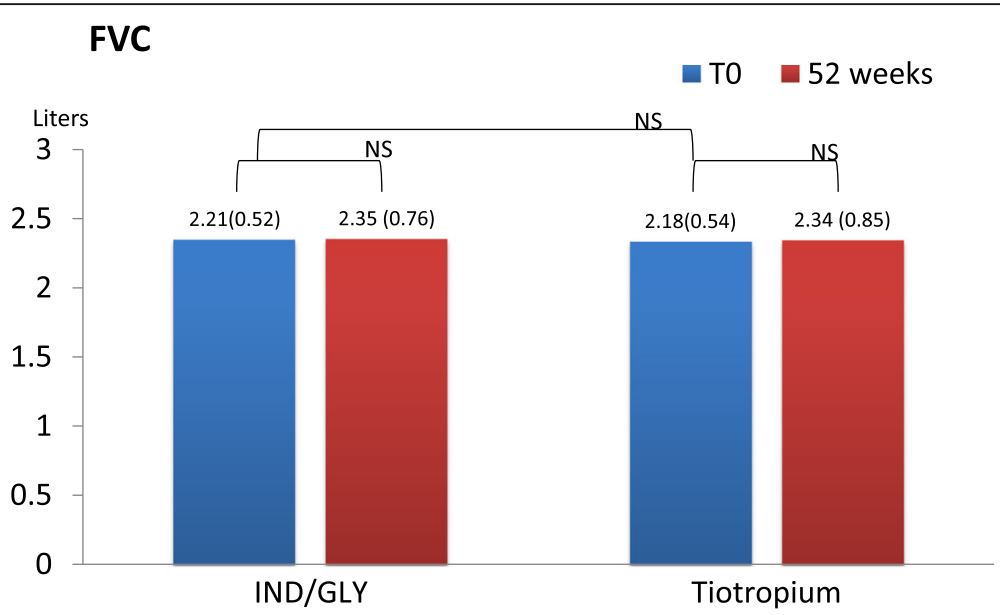

Fig. 4 Pre-dosing FVC (liters and DS) in two groups at $T_{0}$ and after 52 weeks

Raw is not frequently reported in studies evaluating the effect of bronchodilators in COPD. However, this parameter is suggested to be sensitive and to reflect airflow obstruction, particularly of the peripheral airways, more accurately than the $\mathrm{FEV}_{1} / \mathrm{FVC}$ ratio [29]. In assessing the acute functional effect of bronchodilators, specific Raw change-based criteria may be preferable to $\mathrm{FEV}_{1^{-}}$or $\mathrm{FVC}$-based criteria, being more closely related to bronchodilator-induced improvements in lung mechanics and dyspnea at rest.

Other parameters such as R10 and AX have also been shown to change in response to the bronchodilators [30, 31].

Manoharan et al., in randomized patients with moderate to severe COPD already taking ICS/LABA to receive addon therapy in cross-over fashion with either TIO $18 \mu \mathrm{g}$ od or ACL $322 \mu \mathrm{g}$ subsequently bid for $2-3$ weeks each, observed no significant differences between randomized treatments in any IOS or spirometry outcomes measured at trough after chronic dosing with TIO and ACL when used as triple therapy in patients with COPD [20].

In our study also the IC, the best parameter related to the reduction of hyperinflation [32], in patients receiving dual bronchodilation was improved. Improved IC is associated with improved exercise endurance and dyspnea [33, 34] and potentially improved long-term outcomes. Furthermore, the improvement in measures of hyperinflation is supported by the BRIGHT study [35] and recently by Salomon et al. [36].

\section{Conclusion}

The oscillometry demonstrated greater sensitivity compared with spirometry for monitoring outcome measures of airway obstruction and the effect of long term therapy. This technique should facilitate the early optimization of therapy and a more personalized therapeutic approach for COPD patients. These data support the use of dual

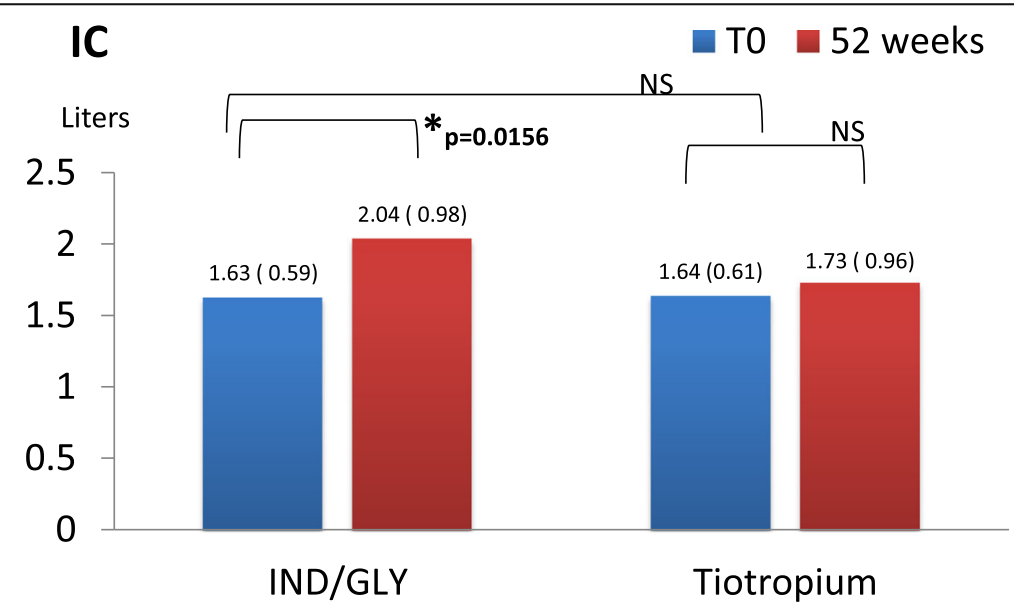

Fig. 5 Pre-dosing IC in two groups at $T_{0}$ and after 52 weeks 


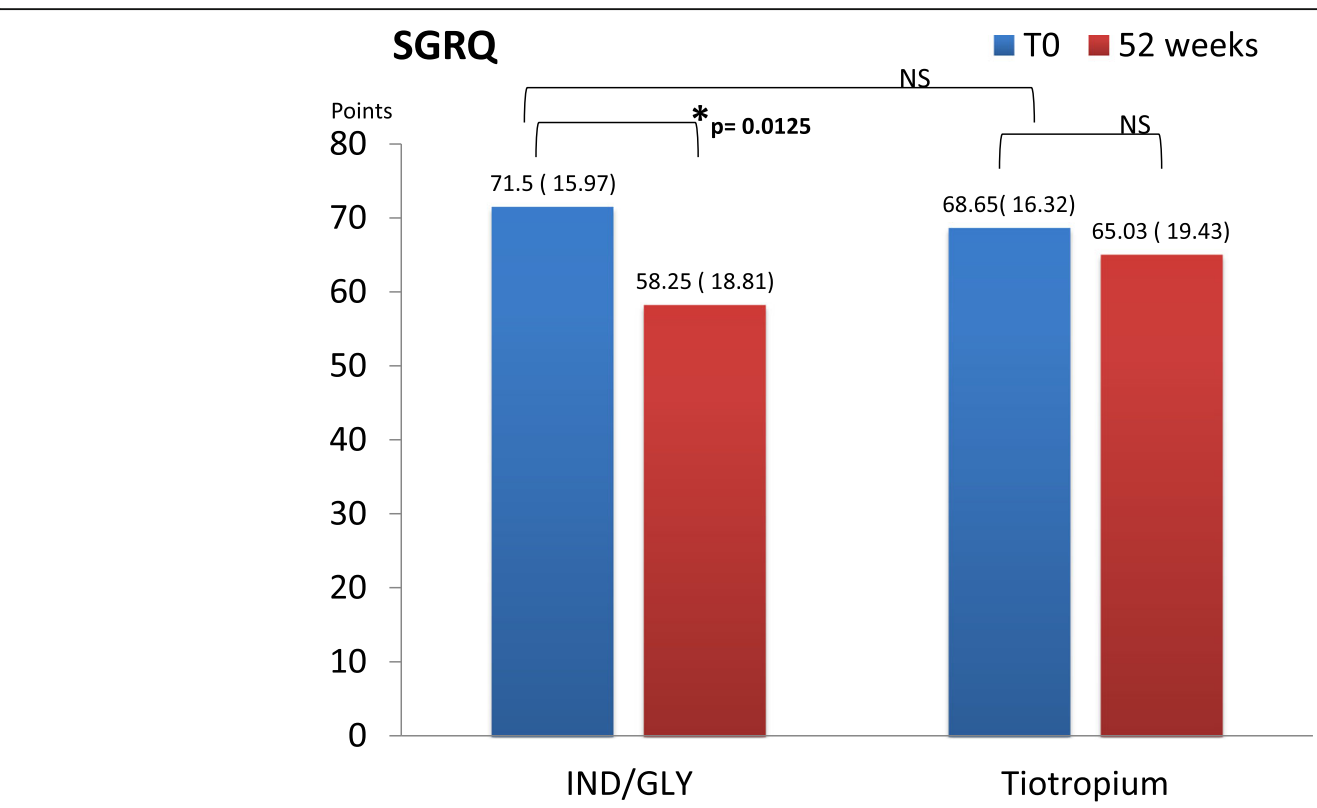

Fig. 6 SGRQ mean difference and DS in two groups at $T_{0}$ and after 52 weeks

bronchodilator therapy to not only improve airways calibre $\left(\mathrm{FEV}_{1}\right)$ but also decrease hyperinflation and its associated negative consequences in patients with COPD.

On the small airways, the combination IND/GLY induces a decrease of dynamic compression, a consequent decrease of dynamic hyperinflation leading to less dyspnea during exercise.

\section{Abbreviations}

BMI: Body mass index; COPD: Chronic Obstructive Pulmonary Disease; $F_{1}$ : Forced expiratory volume in $1 \mathrm{~s}$; FRC: Functional residual capacity; FVC: Forced vital capacity capacity; GOLD: Global Initiative for chronic obstructive Lung Disease; IC: Inspiratory capacity; IND/GLY: Indacaterol/ Glycopirronium; IOS: Impulse oscillometry; LABA: Long-acting beta-agonist; LAMA: Long-acting muscarinic antagonist; SAD: Small-airway dysfunction; SGRQ: St. George's Respiratory Questionnaire; X: Lung reactance

\section{Acknowledgements}

Not applicable.

\section{Funding}

No funding disclosure is to be reported by any of the Authors.

\section{Availability of data and materials}

The Authors do not wish to share their data, without their own permission

\section{Authors' contributions}

All authors read and approved the final manuscript.

\section{Ethics approval and consent to participate}

The study was approved by Ethics Committee (SUN-AO Dei Colli, Naples, Italy) and all subjects gave their written informed consent.

\section{Consent for publication}

Not applicable.

\section{Competing interests}

The authors declare that they have no competing interests.

\section{Publisher's Note}

Springer Nature remains neutral with regard to jurisdictional claims in published maps and institutional affiliations.

Received: 16 May 2017 Accepted: 31 August 2017

Published online: 27 September 2017

\section{References}

1. Vogelmeier CF, Criner GJ, Martinez FJ, Anzueto A, Barnes PJ, Bourbeau J7 et al. Global Strategy for the Diagnosis, Management, and Prevention of Chronic Obstructive Lung Disease 2017 Report. GOLD Executive Summary. Am J Respir Crit Care Med. 2017;195:557-82.

2. Gagnon P, Guenette JA, Langer D, Laviolette L4 Mainguy V, Maltais F, et al. Pathogenesis of hyperinflation in chronic obstructive pulmonary disease. Int J Chron Obstruct Pulmon Dis. 2014:9:187-201.

3. Tantucci C, Donati P, Nicosia F, Bertella E, Redolfi S, De Vecchi M, et al. Inspiratory capacity predicts mortality in patients with chronic obstructive pulmonary disease. Respir Med. 2008;102:613-9.

4. Hogg JC, Chu F, Utokaparch S, Woods R, Elliott WM, Buzatu L, et al. The nature of small-airway obstruction in chronic obstructive pulmonary disease. N Engl J Med. 2004;350:2645-53.

5. Eriksson GJL, Peterson S, Ankerst J, Bjermer L, Tufvesson E. A new approach to assess COPD by identifying lung function break-points. Int J Chron Obstruct Pulmon Dis. 2015;10:2193-202.

6. Frantz S, Nihlén U, Dencker M, Engström G, Löfdahl CG, Wollmer P. Impulse oscillometry may be of value in detecting early manifestations of COPD. Respir Med. 2012;106:1116-23.

7. Pisi R, Aiello M, Zanini A, Tzani P, Paleari D, Marangio E, et al. Small airway dysfunction and flow and volume bronchodilator responsiveness in patients with chronic obstructive pulmonary disease. Int J Chron Obstruct Pulmon Dis. 2015;10:1191-7.

8. Tashkin DP, Celli B, Senn S, Burkhart D, Kesten S, Menjoge S, et al. A 4-year trial of tiotropium in chronic obstructive pulmonary disease. N Engl J Med. 2008;359:1543-54

9. Cazzola M, Molimard M. The scientific rationale for combining long-acting beta2-agonists and muscarinic antagonists in COPD. Pulm Pharmacol Ther 2010:23:257-67.

10. Global Strategy for the Diagnosis, Management and Prevention of COPD, Global Initiative for Chronic Obstructive Lung Disease (GOLD) guidelines; as current in 2008. Available from: http://goldcopd.org. Accessed 26 Mar 2017.

11. Vogel S. Implementation der Sollwertgleichungen für IOS, ImpulsOszillometrie. pmi-Verlag: 1994. p. 148-52. 
12. Hartley RA, Barker BL, Newby C, Pakkal M, Baldi S, Kajekar R, et al. Relationship between lung function and quantitative computed tomographic parameters of airway remodeling, air trapping, and emphysema in patients with asthma and chronic obstructive pulmonary disease: a single-center study. J Allergy Clin Immunol. 2016;137:1413-22. e12

13. Johnson MK, Birch M, Carter R, Kinsella J, Stevenson RD. Measurement of physiological recovery from exacerbation of chronic obstructive pulmonary disease using within-breath forced oscillometry. Thorax. 2007;62:299-306.

14. Miller MR, Hankinson J, Brusasco V, Burgos F, Casaburi R, Coates A, et al. Standardisation of spirometry. Eur Respir J. 2005;26:319-38.

15. Wanger J, Clausen JL, Coates A, Pedersen OF, Brusasco V, Burgos F, et al. Standardisation of the measurement of lung volumes. Eur Respir J. 2005;26:511-22.

16. Crapo RO, Morris AH, Gardner RM. Reference spirometric values using techniques and equipment that meet ATS recommendations. Am Rev Respir Dis. 1981;123:659-64

17. Kamada T, Kaneko M, Tomioka H. Impact of exacerbations on respiratory system impedance measured by a forced oscillation technique in COPD: a prospective observational study. Int J Chron Obstruct Pulmon Dis. 2017;12:509-16

18. Welling JB, Hartman JE, Hacken NH, Klooster K, Slebos D. The minimal important difference for the St George's Respiratory Questionnaire in patients with severe COPD. Eur Respir J. 2015;46:1598-604.

19. Gastaldi AC, et al. Oscillating positive expiratory pressure on respiratory resistance in chronic obstructive pulmonary disease with a small amount of secretion: a randomized clinical trial. Medicine (Baltimore). 2015;94:e1845.

20. Manoharan A, Morrison AE, Lipworth BJ. Effects of adding tiotropium or aclidinium as triple therapy using impulse oscillometry in COPD. Lung. 2016;194:259-66.

21. Mahler DA, Decramer M, D'Urzo A, Worth H, White T, Alagappan VK, et al. Dual bronchodilation with QVA149 reduces patient-reported dyspnoea in COPD: the BLAZE study. Eur Respir J. 2014;43:1599-609.

22. Wedzicha JA, Decramer M, Ficker JH, Niewoehner DE, Sandström T, Taylor AF, et al. Analysis of chronic obstructive pulmonary disease exacerbations with the dual bronchodilator QVA149 compared with glycopyrronium and tiotropium (SPARK): a randomised, double-blind, parallel-group study. Lancet Respir Med. 2013;1:199-209.

23. Bateman ED, Ferguson GT, Barnes N, Gallagher N, Green Y, Henley M, et al. Dual bronchodilation with QVA149 versus single bronchodilator therapy: the SHINE study. Eur Respir J. 2013;42:1484-94.

24. L. Jarenback, J. Ankerst, L. Bjermer, E. Tufvesson. Flow-volume parameters in COPD related to extended measurements of lung volume, diffusion, and resistance. Pulm Med. 2013;2013:782052.

25. Crisafulli E, Pisi R, Aiello M, Vigna M, Tzani P, Torres A, et al A. Prevalence of Small-Airway Dysfunction among COPD Patients with Different GOLD Stages and Its Role in the Impact of Disease. Respiration. 2017;93:32-41.

26. Gong SG, Yang WL, Liu JM, Liu WZ, Zheng W. Change in pulmonary function in chronic obstructive pulmonary disease stage 0 patients. Int J Clin Exp Med 2015:8:21400-6.

27. Kastelik JA, Aziz I, Ojoo JC, Morice AH. Evaluation of impulse oscillation system: comparison with forced oscillation technique and body plethysmography. Eur Respir J. 2002;19:1214-5.

28. Kolsum U, Borrill Z, Roy K, Starkey C, Vestbo J, Houghton C, et al. Impulse oscillometry in COPD: identification of measurements related to airway obstruction, airway conductance and lung volumes. Respir Med. 2009;103:136-43.

29. Desiraju K, Agrawal A. Impulse oscillometry: the state-of-art for lung function testing. Lung India. 2016;33:410-6.

30. Oppenheimer BW, Goldring RM, Berger Kl. Distal airway function assessed by oscillometry at varying respiratory rate: comparison with dynamic compliance. COPD. 2009;6:162-70.

31. Song TW, Kim KW, Kim ES, Park JW, Sohn MH, Kim KE. Utility of impulse oscillometry in young children with asthma. Pediatr Allergy Immunol. 2008;19:763-8.

32. Macklem PT. Therapeutic implications of the pathophysiology of COPD. Eur Respir J. 2010;35:676-80.

33. O'Donnell DE. Hyperinflation, dyspnea, and exercise intolerance in chronic obstructive pulmonary disease. Proc Am Thorac Soc. 2006;3:180-4.

34. O'Donnell DE, Laveneziana P. The clinical importance of dynamic lung hyperinflation in COPD. COPD. 2006:3:219-32
35. Mahler DA, D'Urzo A, Bateman ED, Ozkan SA, White T, Peckitt C, et al. Concurrent use of indacaterol plus tiotropium in patients with COPD provides superior bronchodilation compared with tiotropium alone: a randomised, double-blind comparison. Thorax. 2012;67:781-8.

36. Salomon J, Stolz D, Domenighetti G, Frey JG, Turk AJ, Azzola A. Indacaterol and glycopyrronium versus indacaterol on body plethysmography measurements in COPD—a randomised controlled study. Respir Res. 2017;18:13.

\section{Submit your next manuscript to BioMed Central and we will help you at every step:}

- We accept pre-submission inquiries

- Our selector tool helps you to find the most relevant journal

- We provide round the clock customer support

- Convenient online submission

- Thorough peer review

- Inclusion in PubMed and all major indexing services

- Maximum visibility for your research

Submit your manuscript at www.biomedcentral.com/submit

) Biomed Central 